\title{
A Framework for Construction Workspace Management A Serious Game Engine Approach
}

\author{
Read More: http://ascelibrary.org/doi/abs/10.1061/9780784412343.0008 \\ R. D. Chavada ${ }^{1}$, M. Kassem ${ }^{1}$, N.N. Dawood ${ }^{1}$ and K. K. Naji ${ }^{2}$ \\ ${ }^{1}$ Centre for Construction Innovation Research (CCIR), School of Science and \\ Engineering, Teesside University, Middlesbrough TS1 3BA, UK, PH (+44-1642) \\ 342494 \\ \{R.Chavada, M.Kassem, N.N.Dawood\}@tees.ac.uk \\ ${ }^{2}$ Department Of Civil \& Architectural Engineering, Qatar University, PH: (+974) \\ 4851990, email: knaji@qu.edu.qa
}

\begin{abstract}
Construction workspace is regarded as one of the main constraints on construction sites. Construction workspaces are generally difficult to proactively plan and manage due to the dynamic nature of a site where workspace requirements keep changing as time evolves. However, project managers are looking for ways to develop proactive site plan for the workspaces required for construction activities as this can impact not only on the cost and project duration, but can also contribute to provide a safer site. This research paper presents an approach for integrating workspace management within the planning process using a serious game engine technology. This paper first illustrates a review of the workspace management practices and advanced visualization techniques in the construction industry. Then, it presents a process framework for an interactive decision support system that integrates workspace planning into 5D planning in order to enable safer, efficient and more productive construction sites. The decision support system will identify schedule conflicts, workspace conflicts and the severity of their conflicts, and workspace congestions on a construction site and allow construction planners to resolve spatial conflicts prior to construction. Finally, the paper shows the current progress in the development of an initial prototype and outlines the future work and research.
\end{abstract}

\section{KEYWORDS}

Construction workspace, 4D/5D Planning, Construction Workspace Management, Serious Game Engine.

\section{INTRODUCTION}

Construction projects are complex and dynamic in their nature. One of the main resources and constraints that affect the delivery of construction projects is the space available on site (Dawood et al., 2005). Construction projects are currently characterized by a high degree of fragmentation and specialization, which shape both the work on construction site and the upstream supply chains (Kassem and Dawood., 2012). Construction activities on site are being performed by multiple trades that 
may require, at any point in time, different workspaces as working areas for labor or working space areas for material storage, people, equipment and support infrastructures. Given the complexity and dynamicity of this problem, project managers cannot often predict solutions by relying on experience only. Current space-time planning techniques involve mainly textual description, hand sketches with site layout templates, bar charts, network diagrams, and 2D/3D scaled visualization models. Current construction planning techniques like Gantt chart, network diagrams, and CPM are proven to be inadequate for construction execution space planning. Therefore, project managers require a structured approach and new project management tools that allow them to analyze, detect, control and monitor workspace conflicts (Dawood and Mallasi, 2006). A serious game engine is a game designed for a primary purpose other than pure entertainment (Sawyer and smith, 2008). This paper presents a framework that enables the management of construction workspaces within a serious game engine by integrating the traditional planning (CPM), BIM data of construction models and providing real time visual rehearsal of construction workspace.

\section{LITERATURE REVIEW}

This section presents an extensive and critical literature review of previous works related to both the workspace management and the advanced visualization technologies used in construction workspace planning. In the context of this research, construction workspace management refers to the workspace generation, the workspace assignment or allocation, the workspace conflict detection and resolution at any time during a construction project. The works reviewed were assessed against a number of features grouped under six main categories which are: physical constraints, workspace planning, construction planning, algorithms, knowledge databases and visualization. The results of this review were plotted into a matrix grid illustrated in table 1. The main findings are discussed in the following two sub sections. For the scope of this paper, only a few works are discussed. For all the other works, readers can refer to the matrix grid and referenced papers.

\subsection{Construction Workspace Management}

Moon et al. (2009) proposed an integrated approach where workspace are assigned individually for model's objects and linked to schedule activities. They classified the workspaces and allocated workspaces using a semi-automatic generation method based on resource requirements. This approach has significant drawbacks related to the fact that the workspace is assigned using the bounding volume of a selected object and is performed for each object individually. Planners in practice tend also to identify the required workspaces not only based on model objects but also on schedule activities. Finally, their approach is based on AutoCAD rather than BIM and lack strategies for conflict resolution. Dawood and Mallasi (2006) presented a critical space-time analysis (CSA) approach which was developed to model and quantify space congestion and was embedded into a computerized tool called PECASO (patterns execution and critical analysis of site space organization). This was developed to assist project managers in the assignment and identification of workspace conflicts. This methodology uses a structured query language (SQL) to 
organize the product's coordinates to the required execution sequence, assigns workspaces using layering within the AutoCAD model, and then links workspaces to activities to provide a $4 \mathrm{D}$ construction simulation of processes. While this approach is theoretically capable to deal with the dynamicity of construction workspace, it might be difficult to implement in practice as the project planner is required to assign construction workspaces in the design authoring tool (i.e. AutoCAD).

Table 1 : Matrix of key research in construction workspace management and advanced visualization system

\begin{tabular}{|c|c|c|c|c|c|c|c|c|c|c|c|}
\hline & 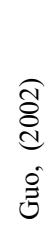 & 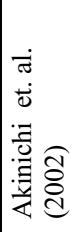 & 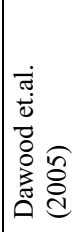 & 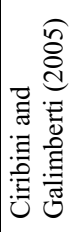 & 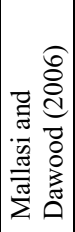 & 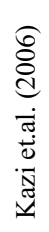 & 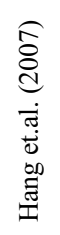 & 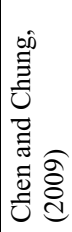 & 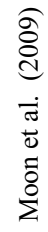 & 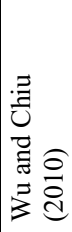 & 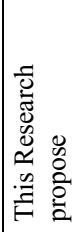 \\
\hline \multicolumn{12}{|l|}{ Physical } \\
\hline People & & & & $\mathrm{X}$ & & $\mathrm{X}$ & & $X$ & & $\mathrm{X}$ & $\mathrm{X}$ \\
\hline $\begin{array}{l}\text { Technological } \\
\text { dependencies }\end{array}$ & $\mathrm{X}$ & $\mathrm{X}$ & $\mathrm{X}$ & $\mathrm{X}$ & $\mathrm{X}$ & $\mathrm{X}$ & $\mathrm{X}$ & $\mathrm{X}$ & $\mathrm{X}$ & $\mathrm{X}$ & $\mathrm{X}$ \\
\hline \multicolumn{12}{|l|}{ Workspace Management } \\
\hline \multicolumn{12}{|l|}{ Workspace Assignment } \\
\hline $\begin{array}{l}\text { 2D/3D Mark-up on CAD } \\
\text { Drawings }\end{array}$ & $\mathrm{X}$ & & $\mathrm{X}$ & & $\mathrm{X}$ & & & $\mathrm{X}$ & & $\mathrm{X}$ & \\
\hline 4D Mark-up tool & & $\mathrm{X}$ & & & & & & & $\mathrm{X}$ & & $\mathrm{X}$ \\
\hline \multicolumn{12}{|l|}{ Workspace Conflict Detection } \\
\hline Physical Conflicts on site & & & & & & & & $\mathrm{X}$ & $\mathrm{X}$ & $\mathrm{X}$ & $\mathrm{X}$ \\
\hline Logical Conflicts on site & & & & & $\mathrm{X}$ & & & & $\mathrm{X}$ & & $\mathrm{X}$ \\
\hline Resources & $\mathrm{X}$ & & $X$ & & $\mathrm{X}$ & $\mathrm{X}$ & & $\mathrm{X}$ & $\mathrm{X}$ & $\mathrm{X}$ & $\mathrm{X}$ \\
\hline Schedule Conflict Detection & $\mathrm{X}$ & & $\mathrm{X}$ & & & & & & $\mathrm{X}$ & $\mathrm{X}$ & $\mathrm{X}$ \\
\hline Conflict Visualisation & & & & & & & & $\mathrm{X}$ & $\mathrm{X}$ & $\mathrm{X}$ & $\mathrm{X}$ \\
\hline Resolution Strategies & $\mathrm{X}$ & & & & & & & & & & $\mathrm{X}$ \\
\hline \multicolumn{12}{|l|}{ construction planning } \\
\hline Planning and scheduling & $\mathrm{X}$ & $\mathrm{X}$ & $\mathrm{X}$ & $\mathrm{X}$ & $\mathrm{X}$ & $\mathrm{X}$ & $\mathrm{X}$ & & $\mathrm{X}$ & $\mathrm{X}$ & $\mathrm{X}$ \\
\hline Monitoring and Controlling & & & & & & & & & & $\mathrm{X}$ & $\mathrm{X}$ \\
\hline "What-If" modelling & & & & & $\mathrm{X}$ & $\mathrm{X}$ & & & & & $\mathrm{X}$ \\
\hline \multicolumn{12}{|l|}{ Optimisation } \\
\hline Computational & & & & & & $\mathrm{X}$ & X & $\mathrm{X}$ & & & $\mathrm{X}$ \\
\hline $\begin{array}{l}\text { AI and Knowledgebase } \\
\text { algorithms }\end{array}$ & & & & & $\mathrm{X}$ & & & & & & \\
\hline \multicolumn{12}{|l|}{ Database } \\
\hline Resource and design DB & & & & $\mathrm{X}$ & $\mathrm{X}$ & $\mathrm{X}$ & & & & & $\mathrm{X}$ \\
\hline \multicolumn{12}{|l|}{ Visualisation } \\
\hline $2 \mathrm{D} / 3 \mathrm{D}$ view & $X$ & & & & & & & & & & \\
\hline $4 \mathrm{D} / \mathrm{VR}$ & & $X$ & $X$ & $X$ & $X$ & $\mathrm{X}$ & $X$ & & $\mathrm{X}$ & $\mathrm{X}$ & $\mathrm{X}$ \\
\hline
\end{tabular}




\begin{tabular}{|l|l|l|l|l|l|l|l|l|l|l|l|}
\hline Game Engine & & & & & & & & $\mathrm{X}$ & & & $\mathrm{X}$ \\
\hline
\end{tabular}

\subsection{Advancement Visualization Technologies}

Kuan-Chen and Shih-Chung (2009) argued that the construction processes are getting more complicated due to the high number of objects including structural elements and equipments. They proposed an algorithm called "VC-COLLIDE" which identifies conflicts on static or dynamic construction sites and determines the distance between large dynamic 3D objects in virtual construction sites using different scenarios. This algorithm rehearses the operation sequence to detect the collision status in real-time virtual construction processes. However, this method 
neither accounts for any risk assessment method nor refer to H\&S issues such as critical space analysis. Dawood et. al. (2005) proposed an innovative advanced planning tool called "VIRCON" (VIRtual CONstruction) which investigates sequential, spatial, process conflicts and temporal aspects of construction schedules before commencing the work on the site. It allows planners to rectify and trade off the temporal sequencing of tasks with their spatial distribution to rehearse the project schedule. However, this does not visualize the conflicts in the 3D environment and does not refer to safety issues in the space analysis.

The literature review illustrated in this paper clearly showed the importance of proactively managing site workspaces. However, most of the existing research have significant limitations as to their approaches for assigning workspaces; the environment in which workspace management is performed; the lack of a resolution strategy as part of their methodology. In fact, some of the existing researches have attempted to generate and assign workspaces in the design authoring tool to which project planners do not often have access to or do not use. Also, in existing research, the workspace is assigned for each object individually (object by object) which is not often the case and can be impractical for models with a high number of components. In addition, there are workspaces that cannot be represented using this method such as storage workspaces as they are not associated with any model's object. Another important limitation of most existing works is that workspace management is separated from the traditional scheduling/planning process and geometric information is imported from non BIM platforms. The framework presented this paper aims at enabling construction workspace management by integrating the traditional planning process $(\mathrm{CPM})$ and BIM data of construction models in a serious game engine and providing real time rehearsal of construction workspaces.

\section{A BIM FRAMEWORK FOR WORKSPACE MANAGEMENT AND VISUALIZATION}

Figure 1 presents the process framework to explain 4D/5D modelling, workspace generation/allocation, spatial-temporal conflicts, workspace congestion and resolution strategies. The model data is imported from BIM tools using a number of different file formats including the IFC format (Industrial Foundation Class - rules and protocols that describe the different building objects) and the schedule information from the planning applications using the XML format. Then, the model data and schedule information are linked together to create a 4D model. A 4D model is a visual simulation of the construction schedule that can be enabled once 3D objects from the 3D model are linked to construction activities from the project schedule. The 4D environment considered for the development of workspace management allows for multiplicity linking between objects and activities - more than one 3D element linked to a single activity and vice versa (Benghi and Dawood, 2008). Once the 4D model has been built in the 4D environment, the processes of construction workspace management can then start. The workspace management will be enabled through a number of processes and sub processes including workspace generation process, workspace and schedule conflict detection process, workspace 
congestion detection process, and resolution strategies process. Each of these processes will be discussed briefly in the following sub- sections.

3.1 Workspace generation: This process starts with the allocation of resources (workers, equipments and materials) and the identification of the required support infrastructures to each activity that affect the dimension, position and type of workspace. The framework assumes that project planners are capable or have access to such information once the construction method has been defined. This metadata information is then used to assign the workspaces through a 3D mark up within the 4D environment. A bounding box will then be created as a result of the $3 \mathrm{D}$ mark-up process. All the different types of workspaces defined earlier can be assigned with a number of options that allow to editing the workspace attributes such as its volume, shape and position. The positioning of the workspace within the 4D environment can be obtained using a transformation matrix. Once the workspace has been generated and positioned, it can then be linked to one or more than one activity in the schedule. In order to enable the subsequent processes for workspaces management, the attributes of each workspace, the model element(s) and activity(ies) to which the workspace was allocated, are stored in a relational database. Once this process has been completed, the workspace conflict detection process can be started.

3.2 Workspace-Schedule conflict and workspace congestion algorithms: A schedule conflict is referred to a situation where a schedule presents a number of overlapping tasks. A workspace conflict may occur only for overlapping tasks sharing the same space. Therefore, the schedule conflict is a preliminary condition that requires to be checked prior to the workspace conflict. Therefore, the first step in the workspace conflict detection process (figure 1) is to check the schedule conflicts. An intersection test aims basically at detecting the physical clash or geometric conflict among the workspaces associated with the conflicting activities. This conflict can be detected by carrying an intersection test in each of the Cartesian direction $(\mathrm{X}, \mathrm{Y}, \mathrm{Z})$. The intersection test utilizes a direct comparison of the individual coordinate values of the Axis aligned Bounding Boxes (AABBs). In particular, it compares the minimum and maximum coordinates values along each axis. Workspace congestion is a situation that occurs when the resources allocated to an activity such as labours, materials and equipment requires larger workspace than the available workspace while there are no physical conflicts between the workspaces. Workspace congestion is checked in all cases independently from the occurrence of schedule conflicts and/or workspace conflicts as it may occur also for a single activity which individually occupies a workspace. The process for checking workspace congestion is illustrated in figure 1 . 


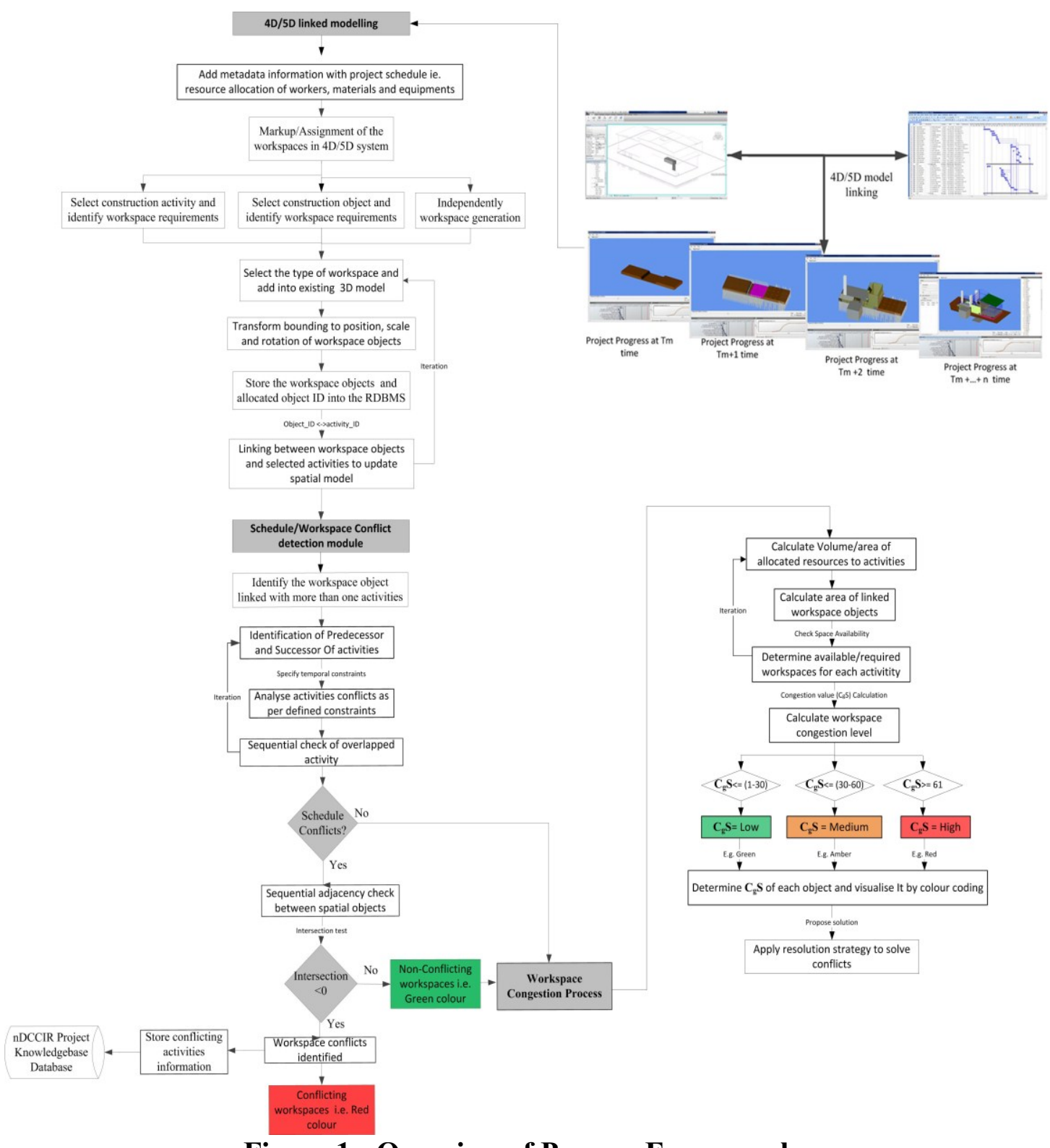

Figure 1 : Overview of Process Framework

\subsection{Resolution of workspace conflicts and workspace congestion}

The resolution of workspace conflicts and workspace congestion represents the last process of construction workspace management where data from previous processes are utilized to resolve conflicts. Although this stage is one of the main aims of construction workspace management, much of the previous research was limited to identify workspace conflicts without tackling resolutions strategies. Bansal (2011) and Guo (2001) included in their methodologies conflict resolution processes that utilize the conflicting activities and the sizes of overlapping construction workspaces. The system will help the decision making process for the following resolution strategies: 
- Adjust/Control schedule: this resolution strategy can be used to resolve schedule and workspace conflicts. The SC value provided for all activities not only help the project planner to focus his resolution strategy on the affected activities but also gives quantitative information about the amount of overlap.

- Adjust/Control physical location: this resolution strategy is used for workspace conflicts/congestion and consists in redesigning, controlling or adjusting the positioning/orientation of workspaces within the model.

- Changing the direction of work progress: many activities and works on construction site can be started from different directions (e.g. south - north rather north - south). Therefore, project planners can resolve workspace conflict by simply changing the direction of work progress.

- Hybrid approach: it is a trade off of the three above strategies.

The outcome from this development is an interactive multidimensional planning tool which allows users to rehearse different real time scenarios of the construction processes before the construction starts. By adopting the proposed methodology and integrating workspace management issues with the traditional planning process, it is hoped that workspace management can be significantly improved on construction site. Once all sub-process of framework developed, industrial pilot case studies will be conducted, in collaboration with practitioners, to test the effectiveness of the system and assess the best ways for its implementation.

\section{CONCLUSION}

One of the main resources and constraints that affect the delivery of construction projects is the space available on site. This paper presented a framework that allows a comprehensive management of construction workspaces by integrating workspace management with the traditional planning process (CPM) and the BIM model in a serious game engine in which construction workspace management is being conducted and rehearsed in visual real-time mode. The result of the review showed that existing research have significant limitations as to their approaches for assigning workspaces; the environment in which workspace management is performed; the lack of resolution strategies as part of their methodology. One of the most important limitations is that workspace management is separated from the traditional scheduling process, the geometric information is imported from non BIM platform, and the workspace management is performed within the design authoring tools. The paper showed the framework organized into a number of processes that explains the workspace generation and allocation process, the workspace conflict detection process, the workspace congestion identification process, and conflict resolution process. This is in line with the principles of $\mathrm{nD}$ project management where the ultimate scope is to give project planners the capability of rehearsing the different construction options before the construction starts in order to enhance the efficiency and productivity of construction processes. 


\section{REFERENCES}

Akinci, B., M. Fischer, J. Kunz, and R. Levitt (2002). Automated Generation of Work Spaces Required by Construction Activities. Journal of Construction Engineering and Management. Vol. 128, No. 4, pp. 306-315.

Bansal, V. K. (2011). Use of GIS and Topology in the Identification and Resolution of Space Conflicts, Journal of Computing in Civil Engineering, Vol. 25, No. 2, pp. $159-171$.

Benghi, C. and Dawood N. (2008). Integration of design and construction through information. technology: from programme rehearsal to programme development. 8th International Conference on Construction Applications of Virtual Reality, Lisbon, Portugal.

Ciribini, A. and Galimberti, G. (2005). 4D Project Planning and H\&S Management, $C I B$ W78's 22nd International Conference on Information Technology in Construction, 19-21 June 2005, Dresden, Germany.

Dawood, N, Scott, D, Sriprasert, E and Mallasi, Z (2005). The virtual construction site (VIRCON) tools: An industrial evaluation. Journal of Information Technology in Construction (ITCon). Vol. 10, Special Issue From 3D to nD modelling, pg. 43-54

Dawood, N. and Mallasi, Z. (2006). Construction workspace planning: assignment and analysis utilizing 4D visualization technology. Computer-Aided Civil and Infrastructure Engineering. Vol. 21, No. 7, October 2006, pp. 498-513.

Huang, T., Kong, C.W., Guo, H.L., Baldwin, A. and Li, H. (2007). A virtual prototyping system for simulating construction processes, Automation in Construction, Vol. 16, No. 5, August 2007, pp. 576-585

Kassem M. and Dawood, N. (2012). A Solution Outline for a Holistic Management and Integration of the Construction Supply Chain IJBPSCM - Special Issue on: "Supply Chain Supported Enhancement of Business Performance". International Journal of Business Performance and Supply Chain Modelling. In PRESS 2012.

Kuan-Chen, L. and Shih-Chung, K. (2009). Collision detection strategies for virtual construction simulation, Automation in Construction, Vol. 18, No. 6, October 2009, pp. 724-736.

Moon, H., Kang, L., Dawood, N. and Ji, S. (2009). Configuration method of health and safety rule for improving productivity in construction space by multi-dimension CAD system, ICCEM/ICCPM, Jeju Korea

Naji, Khalid K. (2006). New Trends in Construction Site Safety and Management Based on Virtual Environments. 6th International Conference on Construction 6th International Conference on Construction Applications of Virtual Reality. 3-4 August 2006, Orlando, Florida, USA.

Sawyer, B. and Smith, P. (2008). Serious game taxonomy. The Serious Games Summit at GDC. [Accessed on 06 December 09] Available at:http://www.seriousgames.org/presentations/serious-games-taxonomy2008_web.pdf.

Sy-Jye Guo (2001). Identification and Resolution of Work Space Conflicts in Building Construction. Journal of Construction Engineering and Management. Vol. 128, No. 4, July/August 2002, pp. 287-29.

$\mathrm{Wu}$, I. and Chiu, Y. (2010). 4D Workspace conflict detection and analysis system. Proceedings of the 10th International Conference on Construction Applications of Virtual Reality, Japan. 